\title{
ASSESSMENT OF A PROPOSED COMPOSITE RESTORATIVE MONOBLOCK APPROACH FOR INTACT ENDODONTICALLY TREATED ANTERIOR TEETH TO OPTIMIZE THEIR ESTHETIC AND FUNCTIONAL OUTCOME WITH BONDED CERAMIC CROWNS. "IN-VITRO STUDY"
}

\author{
Carl Hany Halim*
}

\begin{abstract}
Statement of the Problem: There is general acceptance among different authors about restoring the access cavity of intact endodontically treated anterior teeth with just a composite filling. However, in many instances, for esthetic reasons these teeth need to be crowned. Here, a question is raised about the restorative approach that gives optimum esthetic and functional performance.

Objectives: The aim of the present investigation was to test a proposed monoblock adhesive composite restoration bonded to a prepared channel in the coronal third of the root canal; in comparison to two other conventional approaches: composite filling of the access cavity and glass fiber post in the root canal as far as fracture resistance and failure mode are concerned after the teeth being bonded with CAD/CAM ceramic crowns.
\end{abstract}

Materials and Methods: Twenty-one intact maxillary central incisors were randomly divided into three groups of seven each. All the teeth were endodontically treated to be restored with three different treatment options: in the first group just composite restoration (CR) of the access cavity and the second group was assigned for the proposed monoblock adhesive composite restoration (MACR) and the third group for the glass fiber post bonded in the prepared root canal (GFP). All the teeth were prepared to standardized specifications for CAD/CAM all-ceramic crowns that were adhesively bonded to their preparations in the three groups. All the test specimens were subjected to thermocycling between $5^{\circ} \mathrm{C}$ and $55^{\circ} \mathrm{C}$ for 2000 cycles before being dynamically loaded in the Instron testing machine for 10,000 cycles. The specimens were then subjected to static loading until fracture, and the load at failure $(\mathrm{N})$ of each specimen was recorded for the statistical analysis. The fractured specimens were examined to detect the mode of failure.

Results: All the test samples survived the 10,000 dynamic loading cycles without any signs of cracks or flaws as detected by magnification. The statistical analysis of the data obtained after static loading of the samples revealed that the group with glass fiber posts (GFP) showed the highest

* Associate Professor, Fixed Prosthodontics Department, Faculty of Dentistry, Cairo University 
significant fracture resistance mean value $(579.6 \pm 48.3 \mathrm{~N})$ compared to the other two groups: the conventional $(\mathrm{CR})$ and the proposed design (MACR) that revealed $(415.1 \pm 58.6)$ and (370.6 $\pm 64.2 \mathrm{~N}$ ) respectively, that were not significantly different statistically from each other. The detected mode of failure was an oblique fracture extending from the lingual surface to the labial surface at or just below the insertion of the tooth in the epoxy resin block. The majority of samples (fifteen test sample) presented repairable fractures (71\%) and six samples (29\%) showed nonrepairable fractures. The proposed monoblock design (MACR) presented the highest percentage of repairable fractures $(86 \%)$ followed by the glass fiber post group (GFP) $(71 \%)$ and the least was the conventional group (CR) (57\%).

Conclusions: 1- The three treatment modalities offered successful options for restoring intact endodontically treated maxillary incisors in terms of mechanical and esthetic standpoints. 2- The fracture resistance values of the three tested restorative designs exceeded the normal masticatory forces in this anterior region considerably. 3- The teeth restored with glass fiber posts (GFP) presented the highest statistically significant fracture resistance mean value as compared to the other two groups. 4- The proposed monoblock adhesive composite restoration (MACR) together with the composite restoration (CR) groups provided comparable fracture resistance mean values. 5- The majority of the tested samples $(71 \%)$ showed repairable fractures, with the proposed monoblock technique presenting the highest percentage $(86 \%)$ of repairable fractures. 6 - The mode of failure was mainly adhesive-cohesive in nature.

KEYWORDS: Intact anterior teeth, endodontic treatment, composite monoblock, bonded ceramic crowns.

\section{INTRODUCTION}

Restoration of intact endodontically treated maxillary anterior teeth which lie in the critical esthetic zone presents a great challenge to the fixed prosthodontist in spite of considerable amount of remaining coronal tooth structure. There is general agreement among many authors from a mechanical standpoint that only a simple composite filling can be placed in the access cavity particularly if there is favorable loading and consider this to be the best restorative option..$^{1-3}$ However, endodontically treated teeth (ETT) are subjected frequently to color alterations which give very bad impact on their patient's satisfaction. Therefore, from an esthetic standpoint, extra coronal tooth colored restoration might be recommended.

Ceramic or composite resin veneers are not fairly recommended for endodontically treated anterior teeth because of the presence of the access cavity within the lingual surfaces (Mannocci and Cowie). ${ }^{4}$ Before the great progress that had been achieved in the field of all-ceramic materials and CAD/CAM techniques, together with the adhesive bonding technology; metal-ceramic crowns were commonly recommended for restoring anterior ETT. ${ }^{5}$ This success was referred to their clinical longevity and acceptable esthetics. However, Blatz, ${ }^{6}$ reported that conventional metal-ceramic crowns tend to cause greying of the free gingival margin, caused primarily by the metal substrate. In addition, metals used in these restorations may cause allergic or toxic reactions within adjacent soft or hard tissues. ${ }^{7-10}$

Therefore, with the introduction of advanced ceramics and digital CAD/CAM technology, allceramic restorations offered a highly esthetic appearance, as well as biocompatibility. ${ }^{11-13} \mathrm{To}$ satisfy the best esthetic demands for most of dental patients, it is easier to achieve superb esthetic results with ceramic prosthesis, for example IPS e.max crowns, with less tooth reduction (1.0 to 1.5 $\mathrm{mm}$ ) compared with that of metal-ceramic crowns for anterior restorations (1.2- $1.7 \mathrm{~mm}){ }^{4}$ 
Gonzaga et al, ${ }^{2}$ reported that the prognosis of endodontically treated teeth depends not only on a successful endodontic treatment but also on the amount of remaining sound tooth tissue, together with the definitive restoration that will be placed after that. Does the intact endodontically treated tooth that will be prepared to receive all-ceramic crown for esthetic reasons necessitate an intraradicular post or not is still a matter of debate in the dental literature. ${ }^{15-19}$ The axial reduction for a crown preparation (peripheral destruction) combined with an endodontic access preparation (central destruction) frequently leaves insufficient sound dentin to support a crown unaided. ${ }^{20}$

However, whenever possible preservation of coronal and radicular tooth structure should be considered. Heydecke et al, ${ }^{15}$ and Hunter et al, ${ }^{17}$ clarified the importance of minimal removal of additional radicular dentin while preparing a post space. Further enlargement only weakens the root.

Guzy and Nichols, ${ }^{18}$ and Trope et al, ${ }^{19}$ found that cemented metal posts proved to have no effect on strengthening the root. While, Mannocci et al, ${ }^{21}$ and Saupe et al, ${ }^{22}$ investigated bonding of tooth colored nonmetallic posts to root canal dentin and reported that they strengthen the root initially. However, this initial strengthening might be lost over time as the tooth is subjected to functional loading which leads to weakening of the resin bond to dentin. ${ }^{15}$

Many authors considered that the main function of a post is to build-up a core to retain a crown, however, they reported that it does not strengthen the endodontically treated tooth. ${ }^{19,23-26}$ On the other hand Swartz and Robbins, ${ }^{20}$ reported the great advantages of tooth colored fiber posts compared to metal post systems especially regarding their high flexural strength and modulus of elasticity which are similar to those of dentin. These properties minimize stress transmission to the root canal walls, decrease the possibility of root fracture and improve the esthetic appearance due to avoiding the risk of gingival discoloration or alteration of the root surface by corrosive products.

Composite luting cements as reported by Cecchin et al, ${ }^{27}$ have the ability to bond the fiber post to root canal dentin through providing mechanical retention to dentin with a hybrid layer and chemicomechanical bonding to the post. Oliveira et al, ${ }^{28}$ and Aziz et al, ${ }^{29}$ have shown from their studies that selfetching adhesive is capable of promoting favorable bond strength between the luting composite cement and the dentin. Cecchin et al, ${ }^{27}$ and pashley, ${ }^{30}$ found that failure associated with fiber posts was due to debonding at the adhesive resin-dentin interface. They reported that this might be due to difficulties regarding dentin hybridization caused by irrigants, obstruction of the dentinal tubules, the type of adhesive system and the limited action of light curing achieved in deep root canals. ${ }^{30-32}$ Also, Duke and Lindemuth, ${ }^{33}$ reported that dentin adhesion is unpredictable because of dentin variability in general and radicular dentin in particular. Other authors, ${ }^{34-39}$ referred this compromised dentin bond quality to be due to the morphological differences in radicular dentin which has lesser dentinal tubule density and altered collagen expression therefore, adhesion in the radicular dentin is more problematic as compared to coronal dentin.

Composite resin has been recently considered the most popular core material as it has ideal properties for a build-up material. ${ }^{40,41}$ They reported that it can be bonded to the remaining tooth structure as well as to the current posts. It has high tensile strength and fracture resistance, with favorable fracture pattern if failed. Its color which matches the natural tooth recommends it to be used under translucent restorations with superb esthetic results. On the other hand, other authors reported some inferior properties of composite resin as polymerization shrinkage and water absorption. ${ }^{42}$ Also, the possibility of undergoing plastic deformation under repeated loads. ${ }^{43,44}$ However, more recently with the introduction of nanotechnology which led to 
the discovery of nano-filler particles, considerable advances in physical properties have tackled issues like polymerization shrinkage, wear resistance, micro hardness and esthetic achievement. ${ }^{45,46}$ On the same line, Terry, ${ }^{47}$ reported that the improvement in physical, chemical and biological properties are due to incorporation of a larger volume of small sized filler particles in the composite material. The nanocomposites also possess a higher modulus of elasticity and greater flexural, compressive and diametrical tensile strength. Improvements of fracture toughness, hardness and wear resistance are other advantages of nanocomposites. ${ }^{48}$ The tendency for crack formation and propagation was also reduced due to decreased inter-particle distance between the nanofillers. The smooth and rounded edges of the spheroidal nanoparticles offered better stress distribution throughout the composite resin. ${ }^{49}$ Lesser polymerization shrinkage obtained as a result of increased filler loading in the nanocomposites qualifies them to respond much better to the functional stresses of mastication as compared to the conventional resins. ${ }^{50}$

A noticeable improvement in the esthetic and optical properties of the nanocomposites has been achieved due to incorporating the nano-fillers which significantly improved the polishability, color stability and translucency. ${ }^{51,52}$

All these improvements in the physical, mechanical and esthetic properties qualify the nanocomposites to be successfully used as an esthetic dental restoration in both anterior and posterior teeth. ${ }^{53}$

Dietschi et al, ${ }^{54}$ reported that minimally invasive preparations, with maximal tissue conservation are now considered "the gold standard" for restoring endodontically treated teeth.

Therefore, the main target of the present in-vitro investigation was mainly directed toward mechanical testing of a proposed adhesive composite monoblock technique for restoring intact endodontically treated maxillary central incisors with CAD/CAM ceramic crowns, to be compared with two other conventional designs: one with just composite filling of the access cavity and the other with glass fiber post in the root canal, both covered with ceramic crowns.

The null hypothesis was that there would be no significant difference between the three tested designs concerning their fracture resistance and failure mode.

\section{MATERIALS AND METHODS}

\section{Teeth Selection}

Twenty-one caries-free human maxillary central incisors having comparable dimensions were selected from more than one hundred and fifty extracted teeth for periodontal reasons. The selected teeth were immersed in $5.25 \%$ sodium hypochlorite for 24 hours and subsequently stored in distilled water at room temperature throughout the course of the study. The selected teeth were ultrasonically cleaned and thoroughly examined by the aid of magnifying lens and transillumination to ensure the absence of carious lesions, hypoplastic defects, previous restorations, cracks and micro-fractures. Each tooth was radiographed to detect any internal root resorption or obstructions within the canal. The coronal height was limited to $10 \pm 1 \mathrm{~mm}$ and the root length was between $15 \pm 1 \mathrm{~mm}$ and was measured using a millimeter ruler from the apex to the facial middle point of the cemento-enamel junction. The faciolingual and the mesiodistal dimensions were measured at the level of the cervical margin using a digital caliper (Mitutoyo American Corp, Aurora, III) accurate within $0.01 \mathrm{~mm}$. the faciolingual and mesiodistal dimensions of the selected teeth were as close as possible to 6.5 and $5.5 \mathrm{~mm}$ respectively. ${ }^{55}$

\section{Preparation of the experimental model}

All the teeth were mounted in epoxy resin blocks (Transparent self-curing polyester resin, Acrostonecold cure cross-linked, Egypt) using specially designed cylindrical teflon mold for holding the 
epoxy resin and tooth inside. Accurate centralization of the tooth in the resin block was achieved using a specially designed centralizing device, so that the long axis of the tooth be parallel to the long axis of the sample holder, with the cemento-enamel junction (CEJ) located $2 \mathrm{~mm}$ coronal to the resin top surface. No artificial periodontium was simulated in the present research as recommended by Heintze et al, ${ }^{56}$ Sepastia et al, ${ }^{57}$ who reported that the silicone is not standardizable and varies between 300 and $700 \mathrm{~mm}$. This uncontrolled silicone thickness leads to unstandardized mobility of the single rooted mounted tooth which might lead to unrealistic failure load data. ${ }^{58}$

\section{Endodontic procedure}

All the twenty-one maxillary central incisors mounted in their resin blocks were subjected to a standard endodontic treatment. All the canals were prepared chemo-mechanically using a crown down technique with nickel titanium Flex files up to size 20 (Union Broach, York, Pa.), followed by Ni-Ti rotary instruments (ProTaper up to F5 rotary file, Dentsply, Maillfer). Silicone stoppers were used to control the working length at $1 \mathrm{~mm}$ short of the apical foramen. Root canal obturation was secured using cold lateral condensation technique with F5 ProTaper guttapercha cones (Dentsply, Maillfer, Switzerland) and AH 26 eugenol-free sealer (De Trey; Konstanz, Germany). Post-operative peri-apical radiographs were taken following the endodontic procedure. The twenty-one test specimens were randomly divided into three groups of seven each according to the restorative plan designed for each group (Table 1 and Figure 1) where group I had the access cavity restored with composite filling material (CR), group II was assigned for the proposed monoblock adhesive composite restorative technique (MACR), while in group III glass fiber post was adhesively bonded in the prepared root canal (GFP). The maxillary central incisors in the three groups were then subjected to a standard preparation to receive CAD/CAM e.max ceramic crowns.
TABLE (1) Description of the three experimental groups

\begin{tabular}{|c|l|}
\hline Group & \multicolumn{1}{|c|}{ Restorative Design } \\
\hline I & $\begin{array}{l}\text { Composite filling of the access cavity + CAD/CAM } \\
\text { ceramic crown }(\mathrm{CR})\end{array}$ \\
\hline II & $\begin{array}{l}\text { Proposed monoblock adhesive composite restorative } \\
\text { technique }+ \text { CAD/CAM ceramic crowns (MACR) }\end{array}$ \\
\hline III & $\begin{array}{l}\text { Glass fiber post }+ \text { CAD/CAM ceramic crowns } \\
\text { (GFP). }\end{array}$ \\
\hline
\end{tabular}

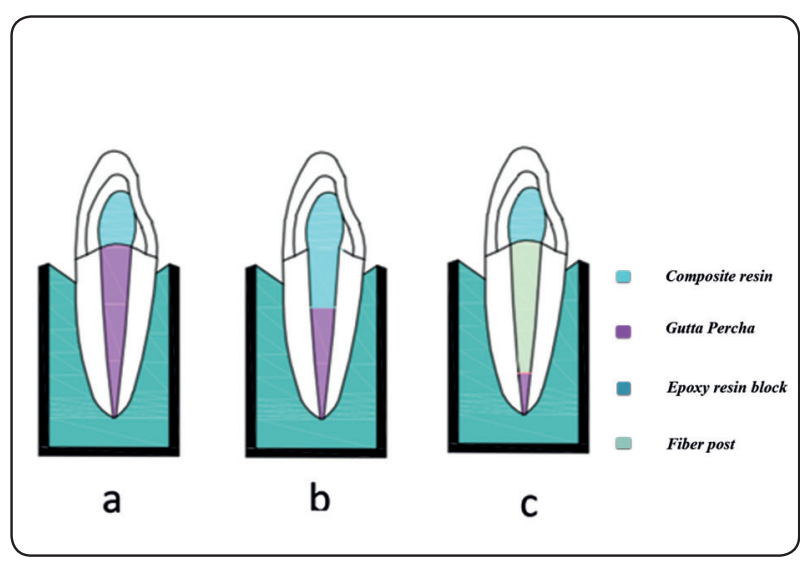

Fig. (1) Schematic drawing of the three tested designs a: group I (CR), b: group II (MACR) and c: group III (GFP)

The first group (CR): This group was considered the control group in which the access cavity was restored with composite restoration. The access cavity was cleaned from the gutta percha and sealer. The cavo-surface margin was beveled using specific diamond bur (TF-14; diamond bur, Mani Inc, Japan) and a constant water spray, and the gutta percha was cut back to osseous level below the CEJ. ${ }^{4}$ Every effort was made to ensure the standard preparation dimensions by using the same instrument size and a single operator. The cavity was then etched with $37 \%$ phosphoric acid etching gel (Ivoclar-Vivadent) for 15 seconds, washed with water spray for another 15 seconds and then gently air-dried with oil free air spray. Conditioning of the cavity was then performed using Syntac Primer (Ivoclar-Vivadent) with a disposable brush and left 
for 15 seconds in contact with dentin, the excess was then removed and the primer dried with oil free air spray. The Syntac Adhesive (Ivoclar-Vivadent) was then applied to the cavity using the disposable brush and left for 10 seconds, then thoroughly dried with oil free air. The bonding agent (Heliobond; Ivoclar-Vivadent) was then applied in a thin layer that was light cured for 20 seconds using the light polymerizing unit (Elipar LED curing unit; 3M ESPE). Flowable composite (Tetric Flow; IvoclarVivadent) was then applied to seal the base of the access cavity and light cured for 40 seconds. The cavity was then restored with light cured composite (Tetric Evo Ceram; Ivoaclar-Vivadent) which is a nano-optimized hybrid moldable ceramic, with low shrinkage and high radiopacity. It was applied in layers using a special contact point instrument, and light cured for 40 seconds. The process was repeated till complete filling of the cavity (Fig 1a). the seven maxillary central incisors of this group were restored in the same manner, then radiographed periapically.

The second group (MACR): This group was assigned for the proposed monoblock adhesive composite restoration (MACR). The access cavity in this group was prepared exactly as in Group I, then a channel extension in the coronal third of root canal was done to a depth of $3 \mathrm{~mm}$. using a tapered flat end medium grit diamond stone having $2 \mathrm{~mm}$. tip diameter and $8^{\circ}$ taper (Mani Dia-Burs-Tochigi-Japan). Cleaning of the whole preparation was then performed with $17 \%$ EDTA (ethylenediaminetetraacetic acid). Etching of the preparation walls was done using $37 \%$ phosphoric acid etching gel for 15 seconds, washed with water spray for another 15 seconds and air dried with oil-free air spray. The following steps were done exactly as described in the first group for the application of the Syntac Primer and Adhesive, then the bonding agent (Heliobond) and application of the flowable composite (Tetric Flow) with the same light polymerization program. The access cavity and the prepared channel were then restored with the light curing composite (Tetric Evo Ceram) in layers using the special contact point instrument to fill the channel at first and then the access cavity. Each layer was light cured for 40 seconds till complete filling of the whole preparation with a compact composite mass (Fig 1b). Periapical radiographs were then taken for the restored teeth.

The third group (GFP): The teeth in this group were restored with glass fiber post (GFP) (FibreKleer Posts, Pentron). This post system provides five post sizes to accommodate different canal sizes, and are designed from uniquely treated glass fibers bundled in a strong resin matrix. It generates an integrated bond among tooth structure, bonding agent, resin cement and composite resin restorative material. These posts have outstanding radiopacity to help insure that they are clearly identified. The post space was first prepared by removal of the gutta percha from the root canal with a peeso reamer, keeping $5 \mathrm{~mm}$ of root filling intact in the apical portion to preserve the apical seal. Then the post space preparation was continued using the calibrated drill supplied with the FibreKleer post system $(1.375 \mathrm{~mm}$ diameter) that matches the size of the selected glass fiber post. The post space was then cleaned with $17 \%$ (EDTA) as in the second group. Cutting excess length of each post was performed using a diamond bur so that at least $2 \mathrm{~mm}$ of composite resin would be covering the post top incisally. Surface treatment of the post was undertaken using total etch for 60 seconds (Ivoclar-Vivadent), then rinsed with water and dried with oil-free air. The post surfaces were then treated using Monobond-S (Ivoclar-Vivadent) for 60 seconds and air dried. Etching of the canal walls was done for 15 seconds then rinsed with water and dried using paper points. The canal walls were painted with Exite DSC (Ivoclar-Vivadent) which is a dual-cure fluoride releasing adhesive used in combination with the total etch technique. The posts were then luted with Tetric Flow, inserted steadily in the prepared post space and light cured for 40 seconds with the tip of the unit directly in contact 
with the post. The access cavity was then restored with Tetric Evo Ceram as described in Group I (Fig 1c). the seven restored teeth in this group were also radiographed periapically.

\section{Tooth Reduction for All-Ceramic Crown Preparation}

The twenty-one experimental models were then ready to start teeth preparations to receive all-ceramic e.max CAD crowns (Ivoclar Vivadent, Schaan, Liechtenstein). A silicone rubber index was made from vinyl polysiloxane putty (Elite HD + A-Silicone, Zhermack- Italy) for recording the coronal configuration of the tooth before being prepared. The silicone index was then sectioned into two equal labial and lingual halves to aid in the standardization of the preparation. A standard set of diamond rotary instruments (Mani Dia- burs, Japan) was used. The axial reduction and the cervical finish line were performed with the aid of the milling machine (Nouvage AF 30, AG Dental and Medical Equipment) to adjust the total incisal convergence at 12 degrees, and to create a one millimeter circumferential round shoulder finish line, located one millimeter above the cemento-enamel junction. Rest of the preparation was performed manually following the standard textbook guidelines, ${ }^{59}$ where the incisal reduction was $2 \mathrm{~mm}$. and the labial and palatal surface were prepared to a depth of one millimeter following the surface configuration after eliminating any undercuts. Final adjustment of the preparation was made with a tapered diamond stone with round end. All the preparation steps were made under constant water spray. To insure standardized dimensions, all the steps were controlled at different measurement points using the digital caliper and the silicone rubber index. (Fig 2).

\section{Construction of the all-ceramic crowns}

The CAD/CAM system "Cerec in Lab" (Sirona dental, Bensheim, Germany) was used for designing and milling of IPS e.max CAD blocks (Ivoclar Vivadent) to produce standard all-ceramic crowns for the prepared teeth. Extraoral inEos X5 scanner (Sirona dental, Germany) was used to capture optical impressions of the prepared teeth that were covered with a thin layer of titanium dioxide powder "Cerec Optispray" (Sirona dental system, Germany) which optimizes image quality. The design of the crowns was performed using the biogeneric feature of the cerec inLab software "Cerec Premium S.W. 4.2.5" to complete the designing process of the allceramic crowns. The design was sent electronically to the milling unit "Cerec MCXL Premium" (Sirona dental, Germany). The milling parameters were set to $60 \mathrm{~mm}$ for the spacer. Following the milling procedure, crystallization of the e.max ceramic crowns was performed according to the manufacturer instructions, then glazed using IPS e.max Ceram glaze paste (Ivoclar Vivadent,

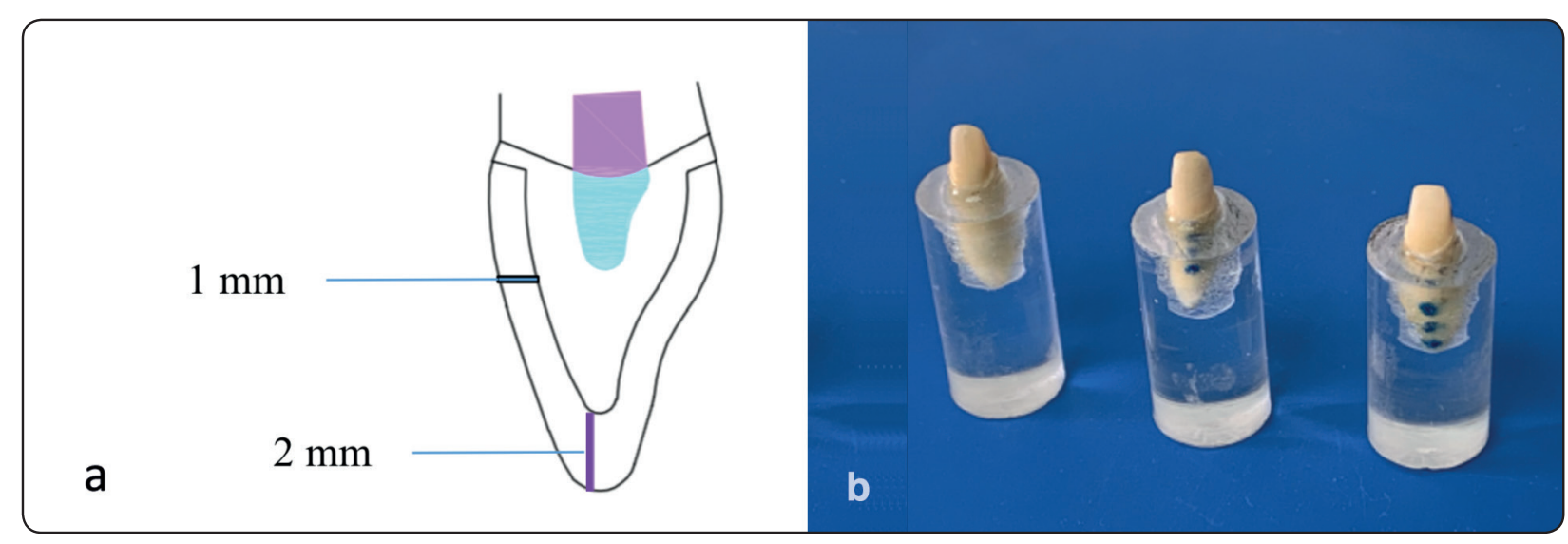

Fig 2: Schematic drawing of standardized tooth preparation (a), and the prepared teeth representing the 3 groups (b). 
Schaan, Liechtenstein) following a standard cooling program. All the milled crowns were then checked for fit and accuracy on their corresponding preparations (Fig 3).

\section{Adhesive bonding of the all-ceramic crowns}

The bonding surface of the ceramic crown was conditioned by etching with IPS Ceramic Etching Gel (5\% hydrofluoric acid) for 15 seconds, then rinsed in water for 30 seconds and dried. Silane coupling agent (Monobond S, Ivoclar Vivadent) was then applied to the etched surface for 60 seconds then was lightly dried with oil free air. The bonding ceramic surface was then brushed with a thin layer of light polymerizing bonding agent (Heliobond). The prepared teeth after being ultrasonically cleaned were then etched with $37 \%$ phosphoric acid for 30 seconds, then cleaned with water spray and dried with oil free air. Syntac Primer was applied and dispersed after 20 seconds, then Syntac Adhesive that was dispersed with air after 10 seconds, after which Heliobond was applied and dispersed with air. The two pastes of the dual curing composite (Variolink II, Ivoclar Vivadent) were mixed and applied evenely on the inner surface of the crown, which was then seated on the prepared tooth and held firmly in place with finger pressure. Excess cement along the margins was gently removed with soft brush, then the seated crown was transferred immediately to a specially designed cementing device through which a $3 \mathrm{Kg}$ static load was applied.

All the surfaces of the crown were then light cured for 40 seconds to complete the bonding procedure. The twenty-one test specimens of the three experimental groups were then subjected to thermal cycling between $5^{\circ} \mathrm{C}$ and $55^{\circ} \mathrm{C}$, with a 25 seconds dwell time at each temperature for 2000 cycles in a computer controlled thermocycler (Robota controlled thermal cycle; Bilge, Turkey) to simulate temperature ranges in the oral environment which can vary between $0^{\circ} \mathrm{C}$ and $67^{\circ} \mathrm{C}$, this represents approximately 12 months of clinical service. ${ }^{60-62}$

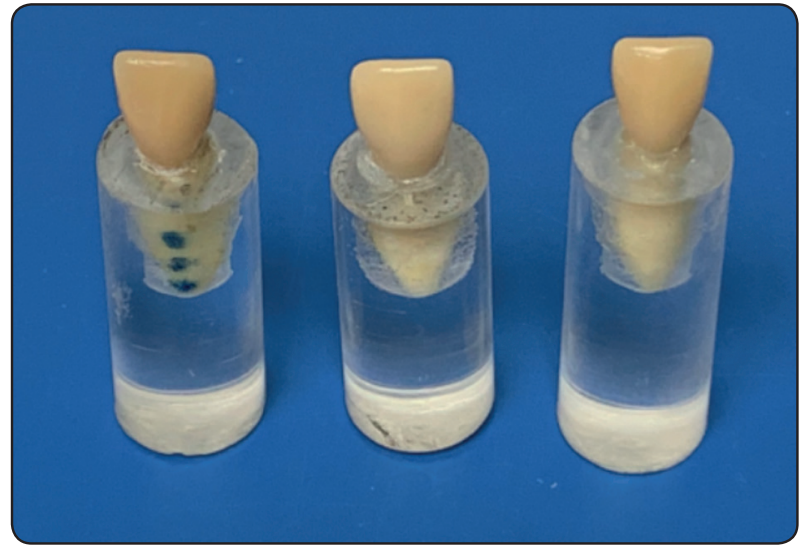

Fig. (3) Milled e.max crowns seated on their prepared teeth after being adjusted, glazed and cemented

\section{Mechanical testing}

The twenty-one test specimens of the three experimental groups, after being thermocycled were individually mounted on the fixed lower compartment of a computer controlled material testing machine (Model 3345; Instron Industrial products, Norwood, MA, USA) with a load cell of 5 $\mathrm{KN}$ and data were recorded using computer software (Instron ${ }^{\mathrm{R}}$ Bluehill Lite software). Cyclic loading of each test sample was secured at a 135-degree angle to their long axis with a 0 to $50 \mathrm{~N}$ load applied at the palatal surface $3 \mathrm{~mm}$ below the incisal edge. The force was applied with a custom made load applicator (steel rod with a round tip $3.4 \mathrm{~mm}$ ) placed at the predetermined point on the palatal surface of the ceramic crown and attached to the upper movable compartment of the machine. A tin foil sheet of 1 $\mathrm{mm}$ thickness was placed between the loading tip and the palatal surface of the test sample to achieve homogenous stress distribution. ${ }^{63,64}$ Each sample received 10000 cycle with a load profile in the form of a sine wave at frequency of $2 \mathrm{~Hz}$ (Fig 4). At the end of the dynamic loading, all the samples were examined visually and with a magnifying lens to detect any possible cracks or fractures. The samples that survived the dynamic loading were subjected to static loading until fracture occurred at a cross head speed of $1 \mathrm{~mm} / \mathrm{min}$. The compressive force was applied at 135 degrees to the long axis at the palatal surface as determined before. The crack initiation 
point on the load deflection curves for all the samples were determined by a sharp decrease in the loading curve and confirmed by an audible sound. The load at the first crack sound was recorded (in Newton) to be the failure load of the test sample. The failure load values of all samples of the three experimental groups were collected and tabulated to be ready for statistical analysis. The fractured samples were examined visually and with a magnifying lens to detect the extent of the cracks and fractures, and photographed with a x5 magnification lens (Sony Digital Still Camera, DSC-H2, Sony Corp, Japan) to aid in the assessment of the fracture patterns and mode of failure of the different test samples.

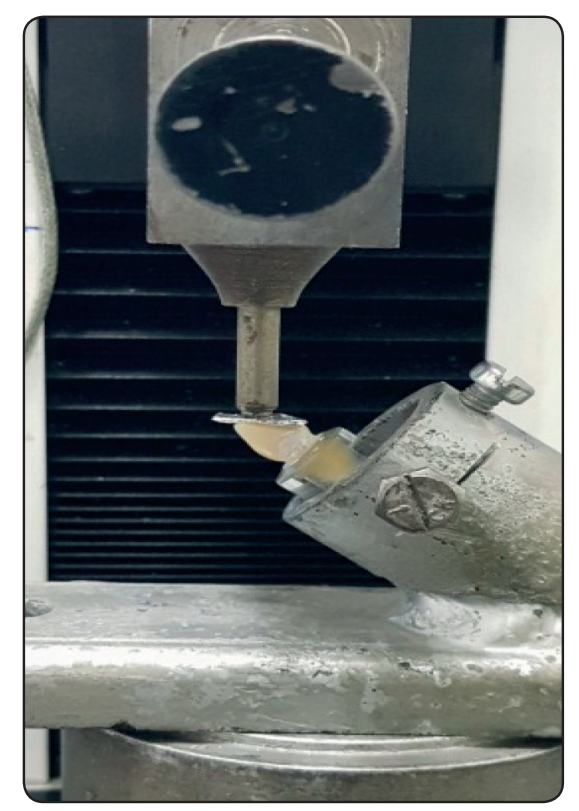

Fig. (4) Mounted sample loaded in the universal testing machine for mechanical testing.

\section{RESULTS}

\section{Statistical Analysis}

Numerical data were explored for normality by checking the data distribution and using Kolmogorov-Smirnov and Shapiro-Wilk tests. Data showed parametric (normal) distribution. Data were represented as mean, standard deviation (SD), median, range and 95\% confidence interval for the mean $(95 \% \mathrm{CI})$ values. One-way ANOVA test was used to compare between the three groups. Bonferroni's post-hoc test was used for pair-wise comparisons. The significance level was set at $\mathrm{P} \leq$ 0.05 . Statistical analysis was performed with IBM SPSS Statistics for windows, version 23.0. Armonk, NY: IBM Corp.

There was a statistically significant difference between the groups $(P$-value $<0.001$, Effect size $=$ 0.741). Pair-wise comparisons between the groups revealed that Group III showed the statistically significantly highest mean fracture resistance value $(579.6 \pm 48.3)$. There was no statistically significant difference between Group I and Group II; both showed the statistically significantly lowest mean fracture resistance values $(415.1 \pm 58.6)$ and (370.6 $\pm 64.2)$ respectively, compared to group III (579.6 \pm 48.3) Table (2) and Figure (5).

The mode of failure of the test specimens in the three groups was nearly the same being an oblique fracture from the palatal aspect to the labial surface

Table (2) Descriptive statistics and result of one-way ANOVA test for comparison between fracture resistance of the three groups $(\mathrm{N})$

\begin{tabular}{|c|c|c|c|c|c|c|c|c|}
\hline \multirow{2}{*}{ Group } & \multirow{2}{*}{ Mean } & \multirow{2}{*}{ SD } & \multirow{2}{*}{ Median } & \multirow{2}{*}{ Range } & \multicolumn{2}{|c|}{$95 \% \mathrm{CI}$} & \multirow{2}{*}{$P$-value } & \multirow{2}{*}{$\begin{array}{c}\text { Effect size } \\
\text { (Eta squared) }\end{array}$} \\
\hline & & & & & Lower bound & Upper bound & & \\
\hline Group I & $415.1^{\text {в }}$ & 58.6 & 407.9 & $347.7-520.2$ & 360.9 & 469.3 & & \\
\hline Group II & $370.6^{\mathrm{B}}$ & 64.2 & 378.5 & $276.5-450.6$ & 311.3 & 430 & $<0.001 *$ & 0.741 \\
\hline Group III & $579.6^{\text {A }}$ & 48.3 & 590.7 & $498.6-640.3$ & 534.8 & 624.3 & & \\
\hline
\end{tabular}

\footnotetext{
*: Significant at $P \leq 0.05$, Different superscripts are statistically significantly different
} 


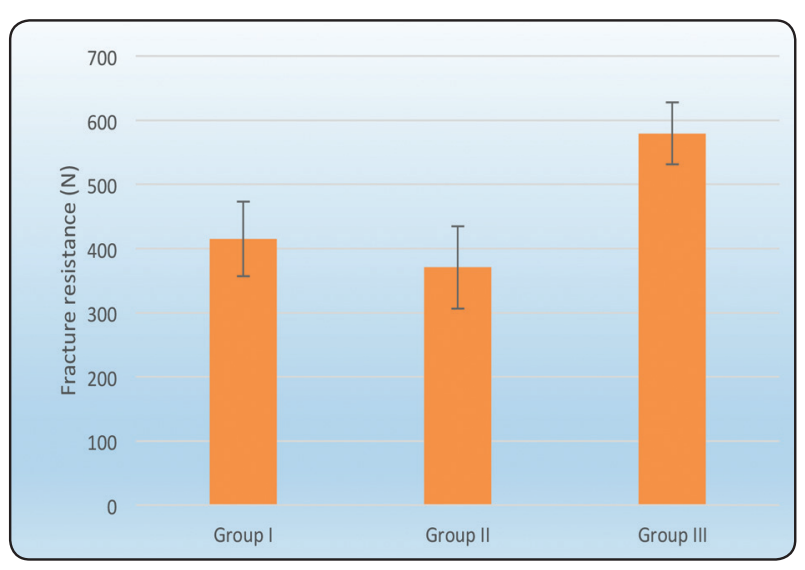

Fig. (5): Bar chart representing mean and standard deviation values for fracture resistance of the three groups

at or just below the insertion of the tooth in the epoxy resin block, which simulated the level of crystal bone (Fig 6). The majority of the specimens (15 test sample) presented repairable fractures (71\%) and six samples only showed non-repairable fractures (29\%). The proposed monoblock design (MACR) presented the highest percentage of repairable fractures $(86 \%)$, followed by the glass fiber post group (GFP) (71\%) and the least was the conventional group (CR) (57\%) Table (3).

TABLE (3) Fracture patterns of the three tested groups

\begin{tabular}{|c|c|c|c|c|c|c|c|c|}
\hline \multirow{2}{*}{$\begin{array}{c}\text { Fracture } \\
\text { Pattern }\end{array}$} & \multicolumn{2}{|c|}{ Group I } & \multicolumn{2}{|c|}{ Group II } & \multicolumn{2}{|c|}{ Group III } & \multicolumn{2}{|c|}{ Total } \\
\cline { 2 - 9 } & No & $\%$ & No & $\%$ & No & $\%$ & No & $\%$ \\
\hline Repairable & 4 & $57 \%$ & 6 & $86 \%$ & 5 & $71 \%$ & 15 & $71 \%$ \\
\hline $\begin{array}{c}\text { Non- } \\
\text { Repairable }\end{array}$ & 3 & $43 \%$ & 1 & $14 \%$ & 2 & $29 \%$ & 6 & $29 \%$ \\
\hline Total & 7 & $100 \%$ & 7 & $100 \%$ & 7 & $100 \%$ & 21 & $100 \%$ \\
\hline
\end{tabular}

Macroscopic examination of the fractured test specimens of the three groups showed catastrophic failures. These failures ultimately resulted from a final loading that exceeded the mechanical capacity of the tooth structure and the ceramic material (Fig $6)$. The general observation of the fractured test

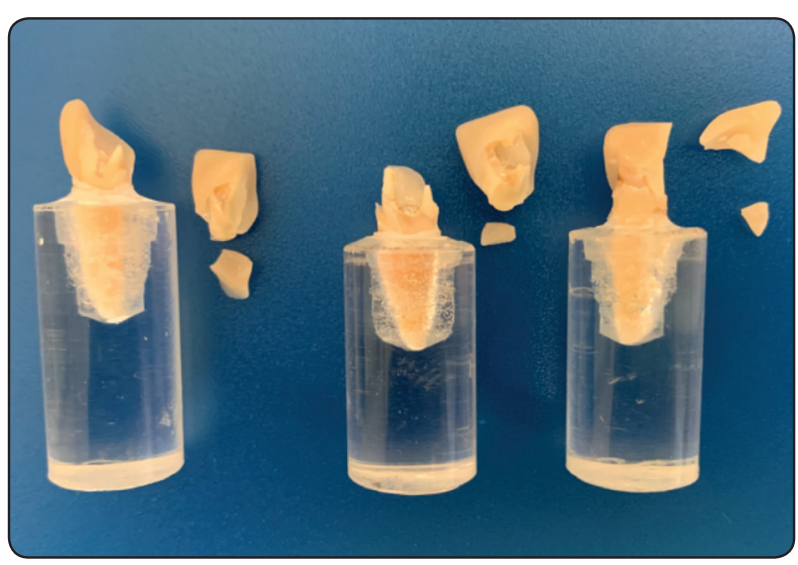

Fig. (6): Representative fractured samples of the three groups

specimens of the three groups revealed nearly the same pattern, where major parts of the ceramic were fractured but still assembled in place, with small tiny separated ceramic fragments. The mode of failure as revealed by X5 magnification lens was mainly adhesive-cohesive in nature, where remnants of the luting cement can be detected on the dentin and fitting surfaces of the test specimens of the three groups (Fig 6).

\section{DISCUSSION}

The ultimate goal of each skillful prosthodontist is to supply his patients with optimum restorations that satisfy both esthetic and functional demands as well as being long lasting. One of the most critical areas that is subjected to many conflict opinions is the restoration of intact endodontically treated teeth.

Sterzenobach et $a l,{ }^{65}$ reported that dentists should read scientific research papers carefully before deciding a specific treatment approach for a postendodontic restoration. Inappropriate line of treatment that is not depending on evidence based data may result in unpredictable clinical results.

Bayne, ${ }^{66}$ and Mjor ${ }^{67}$ considered in vitro studies a valuable tool for determining the mechanical performance of dental restorations that can help in predicting possible preclinical risk problems. Vier, ${ }^{68}$ 
reported that the failure of the majority of restored endodontically treated teeth was due to prosthetic rather than biological reasons.

However, restoration of intact endodontically treated anterior tooth with a ceramic crown for esthetic reasons presents a real challenge to the fixed prosthodontist concerning the optimum treatment approach, whether using a post in the root canal or just a composite filling of the access cavity.

The literature is so rich in this particular area with many conflicting opinions, whether to use posts or not and what type of posts is more convenient.

Since decision making about the most suitable treatment option is becoming so critical and confusing, and in view of the most recent adhesive approaches, the present investigation aimed to test a newly proposed adhesive composite monoblock technique for restoring intact endodontically treated maxillary anterior teeth. This proposed technique was compared with two other traditional techniques: one of them was restored with composite filling in the access cavity, and the other restored with glass fiber post in the root canal. The teeth of the three tested groups were prepared with a standard manner to receive $\mathrm{CAD} / \mathrm{CAM}$ e.max ceramic crowns.

Human teeth were selected in the present research, since other substitutes would behave differently when subjected to mechanical testing particularly to their maximum load capability and failure mode ${ }^{68,69}$ On the other hand, Noumann et al, ${ }^{70}$ considered maxillary central incisors to be an appropriate model for testing the mechanical performance of different restorative systems.

The two restorative techniques used for comparison with the newly proposed monoblock technique were considered by many authors to be convenient for restoring intact ETT, particularly in the esthetic zone. . $^{1-3,21,22,71,72}$

However, when a ceramic crown has to be done for esthetic reasons, many authors, ${ }^{73-76}$ favored the use of glass fiber posts that necessitate intraradicular preparation to be adhesively bonded to root canal dentin for strengthening purpose. The intraradicular preparation together with the extracoronal reduction for the ceramic crown result in the removal of a considerable amount of sound tooth structure..$^{20}$ Therefore, the idea of preserving as much as possible of the radicular dentin has led to this proposal of using the coronal third of the root canal together with the pulp chamber to create an adhesive composite monoblock bulk-fill to be integrated with the root and coronal dentin.

Great care was taken during all the procedural steps of this research to standardize everything starting from teeth selection that have similar dimensions, standard endodontic procedure including access cavity, radicular preparation dimensions and root canal obturation through adopting the rotary protaper system. The following steps of the different experimental groups including post insertion, composite filling and monoblock composite technique were all secured following a thorough adhesive bonding mechanism. The standard CAD/CAM ceramic crowns were also adhesively bonded to the prepared teeth of the three experimental groups, after which they were subjected to a controlled thermal cycling procedure between $5^{\circ} \mathrm{c}$ and $55^{\circ} \mathrm{c}$ for 2000 cycles to simulate the temperature ranges in the oral environment which vary between $0^{\circ} \mathrm{c}$ and $67^{\circ} \mathrm{c} .{ }^{60}$

Since intraoral occlusal forces create dynamic repetitive loading, it was therefore planned in the present investigation for testing the mechanical performance of the ceramic test samples after being thermocycled to subject them to simulated physiologic fatigue load before being subjected to the monotonic static fracture strength test. This allows the evaluation of the ceramic test assembly of the three experimental groups under clinically relevant conditions. The parameters used for the dynamic loading in the present work were guided 
by the physiological values found in the literature. ${ }^{77}$. This presents approximately 15 days to 2 months of clinical service. This dynamic loading was intentionally planned in order to detect any technical invisible defects in the ceramic and to test the integrity of the whole test specimen which might lead to fracture at an early stage that would give a misleading fracture resistance value when subjected to the static loading test.

The statistical analysis of variance (ANOVA) revealed a significant difference between the groups. This indicates that there is a difference in the failure load values resulting from the different treatment modalities of the endodontically treated maxillary central incisors. However, pair wise comparisons between groups revealed that Group III in which glass fiber posts were used showed the highest statistically significant fracture resistance mean value $(579.6 \pm 48.3 \mathrm{~N})$ as compared to the other two groups: I (conventional composite filling) and II (Monoblock composite design) which showed $(415.1 \pm 58.6 \mathrm{~N})$ and $(370.6 \pm 64.2 \mathrm{~N})$ failure load mean values respectively (Table 2 and Figure 5). The mean failure load values of groups I and II were not statistically significant from each other as evident from the statistical analysis. This finding might be in accordance with Sterzenbach et al, ${ }^{65}$ who found that adhesively cemented lithium-disilicate ceramic crowns were more stress resistant when posts were used compared to restoration of ETT without posts even when cyclic loading was performed as also reported by Forbergerand and Gohring. ${ }^{78}$

However, the findings of our research also indicate that restoration of ETT may be possible without the use of a post which agrees with what has been found by Sebastia et al ${ }^{57}$ who reported that this would preserve as much tooth substance as possible and the clinical procedure might be easier to achieve. Juloski et al, ${ }^{79}$ also considered remaining sound tooth structure to be more important than the impact of post and core system, luting agents, and the final restoration on the performance of ETT

In this aspect it is also worth noting that anterior teeth are responsible for tearing and functional guidance as reported by Heydecke et al, ${ }^{15}$ and that fracture resistance of teeth depends on the angle of applied load. Loney et al, ${ }^{80}$ reported that axial forces are less detrimental than oblique forces.

Therefore, the test specimens in the present research were loaded on the palatal surface at an angle of $135^{\circ}$ to the long axis of the root. Goodacre et $\mathrm{al},{ }^{81}$ reported that the maximal occluding force for males exerted by a maxillary incisor tooth was $146 \pm 44 \mathrm{~N}$.

It is then evident from the recorded data of the present research that the two groups that did not receive glass fiber posts (Gr I "CR") and (Gr II "MACR") yielded fracture resistance mean values $(415.1 \pm 58 \mathrm{~N}$, and $370.6 \pm 64 \mathrm{~N})$ that exceeded considerably the normal occluding force in this anterior area.

The most important task of conservative therapy is to restore ETT to resist fatigue forces without failures in the form of root fracture, loss of retention or fracture of the post itself. ${ }^{57}$ In the present research no root fractures were detected in any of the three experimental groups. However, in the third group in which glass fiber posts were used, post failures were in the form of bending rather than fracture. This could be due to matching of the modulus of elasticity of glass fiber posts with that of dentin, which improves the bending resistance, and qualifies the restored tooth when subjected to loading to absorb the forces concentrated along the root and reduce the probability of fracture..$^{82,83}$

It is worth noting in this aspect that the adhesive bonding technique followed in the present research concerning bonding the nano composite filling to dentin of the access cavity (Gr. I) or to the pulp chamber and the prepared channel in the root canal (Gr. II) or for bonding the glass fiber post to root 
canal dentin, followed by bonding the ceramic crowns to the prepared teeth might have an impact on accentuating the fracture resistance mean values of the restored teeth. This might coincide with $\mathrm{Oh}$ and Anucavice, ${ }^{84}$ who reported that the bonding characteristics may affect the fracture resistance and failure mode of ceramic restorations by altering the stress distribution through the substrate and reducing stress concentrations in the ceramic material.

Hwang and Yang, ${ }^{85}$ Burke et al, ${ }^{86}$ and Blatz, ${ }^{6}$ found that resin luting agents have superior mechanical properties and demonstrated increased retentive capabilities, and when used in conjunction with dentin bonding agents increased the fracture resistance of overlying ceramic materials (Groten and Probster). ${ }^{87}$

Ozcan and Vallittu, ${ }^{88}$ referred to the importance of surface conditioning of the ceramic, and reported that adhesion between dental ceramic and luting composite resin is due to a physico-chemical interaction across the interface involving the adhesive and the ceramic surface. Whereas, Foxton et al ${ }^{89}$ and Borges et al,${ }^{90}$ reported that the bonding to lithium disilicate-based ceramics is usually obtained by two simultaneous mechanisms: (1) micromechanical retention provided by acid etching of the ceramic surface with hydrofluoric acid (HF), and (2) chemical coupling by the application of silane coupling agent. Etching and silanization increase the surface energy and wettability of the ceramic substrate which decreases the contact angle between the ceramic and the resin cement (Phoenix and Shen) ${ }^{91}$ and (Soderholm and Shang). ${ }^{92}$

Regarding bonding to dentin, its regional variability in terms of morphological and functional characteristics determines the quality of resin dentin bonds achieved with adhesive systems. Ferrari et $\mathrm{al},{ }^{93}$ and Foxton et $\mathrm{al},{ }^{89}$ reported that the three different bonding sites (crown, cervical finish line, and post space) possess different morphological characteristics, which could influence the bond strength of the adhesive systems. Phrukkanon et al, ${ }^{94}$ and Schupbach et al, ${ }^{95}$ found that the direction of the dentinal tubules played an important role in hybrid layer formation and in increasing the bond strength values.

Bonding esthetic posts to root canal dentin is still a controversial and challenging subject in the clinical practice. The effect of self-adhesive and total-etch adhesive dual cure resin cements on the bond strength of fiber posts to dentin is still a matter of debate. However, Ferrari et al, ${ }^{36}$ and Amiri et al, ${ }^{96}$ found that the bond strength of fiber-post to intracanal dentin was higher after the use of the dual activating system with the total etch technique. The dual-cure self-activating system showed a more uniform resin tag and resin-dentin interdiffusion zone formation along root canal walls than lightcuring systems. ${ }^{36}$

The bonding strategy followed in the present in vitro study was the total-etch and adhesive dualcure resin cement.

The former discussion concerning the bonding procedure clarifies the importance of standardizing all the steps followed to optimize the whole bonding procedure, for its decisive influence on the obtained data.

The fracture patterns obtained in the three experimental groups were the same concerning the mode being an oblique line continued from the palatal aspect of the crown to the labial tooth surface at the insertion into the epoxy resin block (Fig. 6). This finding coincides with Sterzenbach et $\mathrm{al},{ }^{97}$ who explained this fracture pattern to be due to tension palatally and compression facially caused by the palatal loading.

The visual and magnified macroscopic findings of the test specimens of the three groups after being subjected to mechanical testing revealed major fractured ceramic parts that contained remnants of the luting cement on their intaglio surfaces, 
and can be reassembled, and minor ceramic fragments. The exposed dentin surface showed scattered minor remnants of the luting cement (Fig. 6). This denotes that the tooth cement interface appeared to be the weakest link rather than the ceramic cement interface which indicates that the mode of failure was mainly adhesive-cohesive in the three tested groups.

Examination of the broken test specimens of the three groups to classify them as repairable and non repairable ETT (Table 3) revealed that $71 \%$ were repairable and $29 \%$ were considered non repairable. The proposed monoblock design (MACR) presented the highest percentage (86\%) of restorable fractures followed by the glass fiber post group ((GFP) (71\%) and the least was the conventional composite filling group (CR) (57\%) that could be restorable. This high percentage of restorable ETT of the proposed monoblock technique is considered so promising and has important clinical implication since restorable fractures prolong the clinical longevity of endodontically treated teeth. ${ }^{57}$ This might be agreeing with Van Meerbeek et al, ${ }^{97}$ who stated that the true breakthrough in the restoration of endodontically treated teeth was the introduction of adhesion through developing effective dentin adhesives.

Following the same rationale Sevimli et al, ${ }^{98}$ reported that macroretentive elements are no longer mandatory as long as enough surface is available for adhesive bonding. They considered the insertion of radicular posts the exception rather than the rule in conventional restorative techniques. In this aspect also Dietschi et al, ${ }^{54}$ reported about the gold standard for restoring ETT which is the minimally invasive preparations with maximal tissue conservation. However, the results of the present in vitro investigation revealed fracture resistance mean value for the group restored with glass fiber posts that was significantly higher than those of the other two groups inspite of all being exceeding considerably the maximum occluding forces in this area. This might favor the use of glass fiber posts in cases with insufficient amount of remaining tooth structure or in areas with suspected high occlusal stresses, where maximum resistance is needed.

On the other hand, the promising fracture resistance mean values obtained with the proposed monoblock adhesive composite restoration (MACR) encourage the potential of further investigation in this direction where different design features are to be tried with other currently available bondable materials to achieve mechanically homogeneous units with root dentin, in which the term monoblock is applied.

According to the results of this investigation, the null hypothesis stating that there would be no difference in the fracture resistance mean values of the three experimental groups has to be rejected, since the group restored with glass fiber posts showed significantly higher values than the other two groups. However, these two groups: conventional composite filling and the proposed monoblock restoration revealed comparable fracture resistance mean values that are not significantly different.

The other null hypothesis concerning that there is no difference in the failure mode has to be accepted since the fracture line in the test specimens in the three groups was the same having an oblique direction from the palatal aspect to the labial surface of the ceramic crown. The failure mode in all test specimens was mainly adhesive-cohesive in nature.

\section{CONCLUSIONS}

Under the conditions of this in vitro investigation, the following could be concluded:

1- The three treatment modalities tested for restoring intact endodontically treated maxillary central incisors namely composite filling of the access cavity, monoblock adhesive composite restoration and glass fiber post groups that were all covered with CAD/CAM ceramic crowns proved to be successful in terms of mechanical and esthetic stand points. 
2- The fracture resistance values of the three tested restorative designs exceeded the normal masticatory forces in this anterior region considerably.

3- The teeth restored with glass fiber posts (GFP) presented the highest statistically significant fracture resistance mean value as compared to the other two groups.

4- The proposed monoblock adhesive composite restoration (MACR) together with the composite restoration of the access cavity (CR) groups provided comparable fracture resistance mean values.

5- The majority of the tested samples (71\%) showed repairable fractures, however, the proposed monoblock technique presented the highest percentage ( $86 \%$ ) of restorable fractures.

6- The mode of failure was mainly adhesive-cohesive in nature which might be referred to optimizing the adhesive bonding procedure throughout all the preparatory steps of the test samples.

\section{REFERENCES}

1- Rosensteil SF, Land MF, and Fujimoto J: Restoration of the endodontically treated tooth. Contemporary Fixed Prosthodontics, $4^{\text {th }}$ ed, pp 336-378, Mosby, 2006.

2- Gonzaga CC, Campos EA, and Filho FB: Restoration of endodontically treated teeth. RSBO, 2011 Jul-Sep; 8 (3): 33-46.

3- Baba NZ: Restoring endodontically treated teeth. J of Multiple disciplinary Care: Decisions in Dentistry, Jan 2017; 3 (1): $37-42$.

4- Mannoci F, and Cowie J: Restoration of endodontically treated teeth. Br. Dent J; 2014 Mar, 216: 341-346.

5- McLean JW: Evolution of dental ceramics in the twentieth century. J Prosthet Dent, 2001; 85: 61-6.

6- Blatz MB: Long-term clinical success of all-ceramic posterior restorations. Quintessence Int 2002; 33: 415-26.

7- Kansu G, and Aydin AK: Evaluation of the biocompatibility of various dental alloys: Part 1- Toxic potentials. Eur J Prosthodont Restor Dent 1996; 4: 129-36
8- Kansu G, and Aydin AK: Evaluation of the bio compatibility of various dental alloys: Part 2 - Allergenical Potentials. Eur J Prosthodont Restor Dent 1996; 4:155-61.

9- Cai Z, Vermilyea SG, Brantley WA: In vivo corrosion resistance of high-palladium dental casting alloys. Dent Mater 1999; 15:202-10.

10- Fovet Y, Pourreyron L, Gal JY: Corrosion by galvanic coupling between carbon fiber posts and different alloys. Dent Mater 2000; 16: 364-73.

11- Narcisi EM: Three-unit bridge construction in anterior single-pontic areas using a metal-free restorative. Compend Contin Educ Dent 1999; 20: 109-12, 114, 116-20.

12- Segal BS: Retrospective assessment of 546 all-ceramic anterior and posterior crowns in a general practice. $\mathrm{J}$ Prosthet Dent 2001; 85: 544-50.

13- Fradini M, and Redemagni M: An 11-year clinical evaluation of leucite-reinforced glass-ceramic crowns: a retrospective study. Quintessence Int 2002; 33: 503-10.

14- Kayser AF, Leempoel PJ, and Snoek PA: The metal post and composite core combination. Oral Rehabil, 1987; 14: 3-11.

15- Heydecke G, Butz F, Strub JR: Fractur strength and survival rate of endodontically treated maxillary incisors with approximal cavities after restoration with different post and core systems: an in-vitro study. J Dent 2001; 29: 427-33.

16- Sorensen JA, Martinoff JT: Endodontically treated teeth as abutments. J Prosthet Dent 1985; 53: 631-6.

17- Hunter AJ, Feiglin B, Williams JF: Effects of post placement on endodontically treated teeth. J Prosthet Dent1989; 62: $166-72$.

18- Guzy GE, Nichols JL: In vitro comparison of intact endodontically treated teeth with and without endo-post reinforcement. J Prosthet Dent 1979; 42: 39-44.

19- Trope M, Maltz DO, Tronstad L: Resistance to fracture of restored endodontically treated teeth. Endod Dent Traumatol 1985; 1 : 108-11.

20- Swartz RS and Robbins JW: Post placement and restoration of endodontically treated teeth: a literature review. J Endodontics 2004; 30: 289-301.

21- Mannocci F, Ferrari M, Watson TF: Intermittent loading of teeth restored using Quartz fiber, carbon fiber, and zirconium dioxide ceramic root canal posts. J Adhes Dent 1999; 1: $153-8$ 
22- Saupe WA, Gluskin AH, Radke RA Jr: A comparative study of fracture resistance between morphologic dowel and cores and a resin-reinforced dowel system in the intraradicular restoration of structurally compromised roots. Quintessence Int 1996; 27: 483-91.

23- Sorensen JA, Engelman MJ: Ferrule design and fracture resistance of endodontically treated teeth. J Prosthet Dent, 1990; 63: 529-536.

24- Caputo AA, Standlee: Pin and posts - why, when and how. Dent Clin North Am, 1976; 20: 299-311.

25- Sorensen JA, Engelman MJ: Effect of Post-adaptation on fracture resistance of endodontically-treated teeth. J Prosthet Dent, 1990; 64: 419-424.

26- Tjan AH, Whang SB: Resistance to root fracture of dowel channels with various thickness of buccal dentin walls. J Prosthet Dent, 1985; 53: 496-500.

27- Cecchin D, de Almeida JF, Gomes BP, et al: Effect of chlorhexidine and ethanol on the durability of the adhesion of the fiber post relined with resin composite to the root canal. J Endod 2011; 37: 678-83.

28- Oliveira SS, Pugach MK, Hilton JF. et al: The influence of the dentin smear layer on adhesion: a self-etching primer vs a total etch system. Dent Mater 2003; 19:758-67.

29- Aziz TM, Anwar MN, El-Askary FS: Push-out strength of fiber posts to root canal dentin using a one-step self-etching adhesive: the effect of solvent removal and light-curing methods. J Adhes. Dent 2014; 16: 79-86.

30- Pashley DH: Smear layer: physiological considerations. Oper Dent Suppl 1984; 3: 13-29.

31- Ermis RB, De Munck I, Cardoso MV, et al: Bond strength of self-etch adhesives to dentin prepared with three different diamond burs. Dent Mater 2008; 24: 978-85.

32- Zorba YO, Erdmir A, Ahmetoglue F, Yoldas O: Effect of different light sources in combination with a light transmitting post on the degree of conversion of resin composite at different depths of simulated root canals. Dent Traumatol 2011; 27: 195-8.

33- Duke ES, Lindemuth J: Variability of clinical dentin substrates. Am J Dent 1991; 4: 241-6.

34- Ferrari M, Vichi A, Grandini S: Efficacy of different adhesive techniques on bonding to root canal walls: an SEM investigation. Dent Mater 2001; 17: 422-9.

35- Vichi A, Grandini S, Davidson CL, Ferrari M: An SEM evaluation of several adhesive systems used for bonding fiber posts under clinical conditions. Dent Mater 2002; 18: 495-502.
36- Ferrari M, Vichi A, Grandini S, Goracci C: Efficacy of a self-curing adhesive-resin cement system on luting glassfiber posts into root canals: an SEM investigation. Int $\mathrm{J}$ Prosthodont 2001; 14:543-9.

37- Vichi A, Grandini S, Ferrari M: Comparison between two clinical procedures for bonding fiber posts into a root canal: a microscopic investigation. J Endodon 2002; 28:355-60.

38- Mannocci F, Betelli E, Watson TF, Ford TP: Resin-dentin interfaces of endodontically-treated restored teeth. Am J Dent 2003; 16: 28-32.

39- Mjor IA, Smith MR, Ferrari M, Mannocci F: The structure of dentin in the apical region of human teeth. Int Endod J 2001; 34:346-53.

40- Hsu YB, Nicholls JI, Phillips KM, Libman WJ: Effect of core bonding on fatigue failure of compromised teeth. Int $\mathrm{J}$ Prosthodont 2002; 15:175-8.

41- Pilo R, Cardash HS, Levin E, Assif D: Effect of core stiffness on the invitro fracture of crowned, endodontically treated teeth. J Prosthet Dent 2002; 88: 302-6.

42- Oliva RA, Lowe JA: Dimensional stability of silver amalgam and composite used as core materials. J Prosthet Dent 1987; 57: 554-9.

43- Kovarik RE, Breeding LC, Caughman WF: Fatigue life of three core materials under simulated chewing conditions. J Prosthet Dent 1992; 68: 584-90.

44- Gateau P, Sabek M, Dailey B: Fatigue testing and microscopic evaluation of post and core restorations under artificial crowns. J Prosthet Dent 1999; 82: 341-7.

45- Saunders SA: Current practicality of nanotechnology in dentistry. Part 1: Focus on nanocomposite restoratives and biomimetics. Clin. Cosmet. Investig. Dent. 2009; 1, 47-61.

46- Chen, M: Update on dental nanocomposites. J. Dent. Res. 2010; 89, 549-560.

47- Terry DA: Direct applications of nanocomposite resin system: Part 1 - The evolution of contemporary composite materials. Pract Pyoced Aesthet Dent 2004; 16 (6): 417-22.

48- George R: Nanocomposites - A Review. J Dent \& Oral Biosc. 2011; 2 (3): 38-40

49- de Moraes RR, Goncalves Lde S, Lancellotti AC, Consani S, Correr-Sobrinho L, Sinhoreti MA: Nanohybrid resin composites: nanofilles loaded materials or traditional microhybrid resins? Oper Dent 2009; 34 (5): 551-7.

50- Kaur P, Luthra R, Puneet: Nanocomposites - A step towards improved restorative dentistry. Ind J Dent Sci 2011; 4 (3): 28-31. 
51- Mitra SB, Wu D, Holmes BN: An application of nanotechnology in advanced dental materials. J Am Dent Assoc 2003; 134 (10): 1382-90.

52- Mahalaxmi S: Composite resins In Materials used in Dentistry. $1^{\text {st }}$ ed. Wolter Kluwer/ Lipincott Williams \& Wilkins; 2013.

53- Sachdeva S, Kapoor P, Tamrakar AK, Noor R: Nano-composite dental resins: An Overview. Annals of Dental Speciality Vol. 3; Issue 2 Apr - June 2015.

54- Dietschi D, Due O, Krejci I, Sadan A: Biomechanical considerations for the restoration of endodontically treated teeth: A systematic review of the literature, part ii (evaluation of fatigue behavior, interfaces, and in vivo studies). Quintessence Int 2008; 39 (2): 117-129.

55- Ash MM, and Nelson SJ: Wheeler's dental anatomy, physiology and occlusion. $8^{\text {th }}$ ed. Philadelphia: W.B. Saunders; 2003.

56- Heintze SD, Cavalleri A, Zellweger G, Buchller A, Zappini G: Fracture frequency of all-ceramic crowns during dynamic loading in a chewing simulator using different loading and luting protocols. Dent Mater 2008; 24: 1352-1361.

57- Sepastia AR, Bortollotto T, Lorente MC, Giner L, Roig M, Krejci I: Adhesive restoration of anterior endodontically treated teeth: influence of post length on fracture strength. Clin Oral Invest April, 2013.

58- Chang CY, Kuo JS, Lin YS, Chang YH: Fracture resistance and failure modes of Cerec endo-crowns and conventional post and core-supported Cerec crowns. J Dent Sci. 2009; 4 (3): $110-117$.

59- Rosenstiel SF, L and MF, and Fujimoto J: Contemporary Fixed Prosthodontics, Mosby, Inc. St. Louis, Missori, ed. 3, 2001.

60- Wassel RW, McCabe JF, and Walls AW: Wear characteristics in a two-body wear test. Dent Mater 1994; 10: 269-74.

61- Yang R, Arola D, Han Z and Zhang X: A comparison of the fracture resistance of three machinable ceramics after thermal and mechanical fatigue. J Prosthet Dent 2014; 112: 878-885.

62- Vasques VZ, Ozcan M, Kimpara ET: Evaluation of interface characterization and adhesion of glass ceramics to commercially pure titanium and gold alloy after thermal and mechanical loading. Dent Mater 2009; 25: 221-31.

63- Loose M, Rosentritt M, Leibrock A, Behr M, Handel G: In vitro study of fracture strength and marginal adaptation of fibre-reinforced-composite versus all-ceramic fixed partial dentures. Eur J Prosthodont Restor Dent 1998; June; 55-62.
64- Chitmongkolsuk S, Heydeke G, Stappert C, Strub JR: Fracture strength of all-ceramic lithium disilicate and porcelain-fused-to-metal bridges for molar replacement after dynamic loading. Eur J Prosthodont Restor Dent.

65- Sterzenbach G, Rosentritt M, Frankenberger R, Paris S, Naumann M: Loading standardization of postendodontic restorations in vitro: impact of restorative stage, static loading, and dynamic loading. Operative Dentistry, 2012; 37-1, 71-79.

66- Bayne SC: Dental restorations for oral rehabilitation - Testing of laboratory properties versus clinical performance for clinical decision making. J of Oral Rehabilitation 2007; 34 (12) 921-932.

67- Mjor IA: Minimum requirements for new dental materials. J of Oral Rehabilitation 2007; 34 (12) 907-912.

68- Rosentritt M, Naumann M, Hahnel S, Handel G, \& Reill M: Evaluation of tooth analogs and type of restoration on the fracture resistance of post and core restored incisors. Journal of Biomedical Materials Research 2009; Part B, Applied Biomaterials 91 (1) 272-276.

69- Rosentritt M, Reill M, Naumann M, Nowak A, Handel G: Strength investigation of artificial substitutes for human teeth in in vitro studies. International Journal of Prosthodontics 2009; 22 (1) 62-64.

70- Naumann M, Metzdorf G, Fokkinga W, Watzke R, Sterzenback G, Bayne S \& Rosentritt M: Influence of test parameters on in vitro fracture resistance of post-endodontic restorations: A structured review Journal of Oral Rehabilitation 2009; 36 (4) 299-312.

71- Naumann M, Sterzenback G, Alexandra F, \& Dietrich T: Randomized controlled clinical pilot trial of titanium versus glass fiber prefabricated posts: Preliminary results after up to 3 years. International J Prosthodontics; 2007; 20 (5) 499-503.

72- Naumann M, Preuss A, \& Frankenberger R: Reinforcement effect of adhesively luted fiber reinforced composite versus titanium posts. Dental Materials 2007; 23 (2) 138-144.

73- Bitter K, \& Kielbassa AM: Post-endodontic restorations with adhesively luted fiber-reinforced composite post systems: A review American J of Dentistry, 2007; 20 (6) 353 360 .

74- Fokinga WA, Kreulen CM, Vallitto PK, \& Creugers NH: A structured analysis of an in vitro failure loads and failure modes of fiber, metal, and ceramic post-and-core systems. InternationalJ Prosthodontics 2004; 17 (4) 476-482. 
75- GU XH, Kern M: Fracture resistance of crowned incisors with different post systems and luting agents. J Oral Rehabil 2006; 33: 918-23.

76- Maroulakos G, Nagy WW, Kontogiorgos ED: Fracture resistance of compromised endodontically treated teeth restored with bonded post and cores: An in vitro study. J Prosthet Dent 2015; 114 (3): 390-7.

77- Wiskott HW, Nicholls JI, Belser UC: Stress fatigue basic principles and prosthodontic implications. Int J Prosthodont1995; 8: 105-16.

78- Forberger N, and Gohring TN: Influence of the type of post and core on in vitro marginal continuity, fracture resistance, and fracture mode of lithia disilicate-based allceramic crowns. J Prosthet Dent 2008; 100 (4) 264-273.

79- Juloski J, Radovic I, Goracci C, Vulicvic ZR, Ferrari M: Ferrule effect: a literature review. J Endod 2012; 38:11-9.

80- Loney RW, Moulding MB, Ritsco RG: The effect of load angulation on fracture resistance of teeth restored with cast post and cores and crowns. Int J Prosthodont 1995; 8: 247-251.

81- Goodacre CJ, Bernal G, Rungcharassaeng K, Kan JY: Clinical complications in fixed prosthodontics. J Prosthet Dent 2003; 90:31-41.

82- Stewardson DA, Shortall AC, Marquis PM, Lumley PJ: The flexural properties of endodontic post materials. Dent Mater; 2010; 26: 730-736.

83- Chuang SF, Yaman P, Herrero A, Dennison JB, Chang CH: Influence of post material and length on endodontically treated incisors: An in vitro and finite element sty. J Prosthet Dent 2010, 104: 379-388.

84- Oh WS, and Anusavice KJ: Effect of connector design on the fracture resistance of all-ceramic fixed partial dentures. J Prosthet Dent 2002; 16: 150-156.

85- Hwang JW, and Yang JH: Fracture strength of copy-milled and conventional In-Ceram crowns. J Oral Rehabil 2001; 28:678-83.

86- Burke FJ, Fleming GJ, Nathanson D, and Marquis PM: Are adhesive technologies needed to support ceramics? An assessment of the current evidence. J Adhes Dent 2002; 4: $7-22$.
87- Groten M, and Probster L: The influence of different cementation modes on the fracture resistance of felspathic ceramic crowns. Int J Prosthodont 1997; 10:169-77.

88- Ozcan MJ, and Vallittu PK: Effect of surface conditioning methods on the bond strength of luting cements to ceramics. Dent Mater 2003; 19: 725-31.

89- Foxton RM, Pereira PN, Nakajima M, Tajami J and Miura H: Durability of the dual-cure resin cement/ceramic bond with different curing strategies. J Adhes Dent 2002; 4:49-59.

90- Borges GA, Sophr AM, de Goes MF, Sobrinho LC, and Chan DC: Effect of etching and airborne particle abrasion on the microstructure of different dental ceramics. J Prosthet Dent 2003; 89: 479-88.

91- Phoenix RD, and Shen C: Characterization of treated porcelain surfaces via dynamic contact angle analysis. Int $\mathrm{J}$ Prosthodont 1995; 8: 187-94.

92- Soderholm KJ, and Shang SW: Molecular orientation of silane at the surface of colloidal silica. J Dent Res 1993; 72:1050-4.

93- Ferrari M, Mannoci F, Vichi A, Cagidiaco MC, and Mjor IA: Bonding to root canal: structural characteristics of the substrate. Am J Dent 2000; 13: 255-60.

94- Phrukkanon S, Burrow MF, and Tyas MJ: The effect of dentine location and tubule orientation on the bond strengths between resin and dentine. J Dent 1999; 27: 265-74.

95- Schupbach P, Krejci I, and Lutz F: Dentin bonding: effect of tubule orientation on hybrid-layer formation. Eur J Oral Sci 1997; 105: 344-52.

96- Amiri EM, Balouch F, and Atri F: Effect of self-adhesive and separate etch adhesive dual cure resin cements on the bond strength of fiber post to dentin at different parts of the root. J Dent, Tehran Univ. of Med. Sc, Tehran, Iran, 2017; 14: No 3 .

97- Van Meerbeek B, Perdigao J, Lambrechts P, Vanherle G: The clinical performance of adhesives. J Dent 1998; 26 (1): 1-20.

98- Sevimli G, Cengiz S, and Oruç MS: Endocrowns: Review. J Istanbul Univ Fac Dent 2015; 49 (2): 57-63. 